\title{
Machining of Pure High Grade Titanium: Effect on the Subsurface Microstructure
}

\author{
A. Tidu ${ }^{1 *}$, A. De Saever ${ }^{2}$, C. Schuman ${ }^{2}$ B Bolle ${ }^{1}$ and P. Chevrier ${ }^{3}$ \\ ${ }^{1}$ Laboratoire d'Étude des Microstructures et de Mécanique des Matériaux (LEM3), CNRS 7239, École Nationale d'Ingénieurs de Metz (ENIM), 1 \\ route d'Ars Laquenexy, F-57012 Metz Cedex 01, France \\ ${ }^{2}$ Laboratoire d'Étude des Microstructures et de Mécanique des Matériaux (LEM3), CNRS 7239, Université de Lorraine, ile du Saulcy, F-57045
} Metz Cedex 01, France

${ }^{3}$ Laboratoire de mécanique Biomécanique, Polymère Structures (LaBPS), EA 1097, 1 route d'Ars Laquenexy, École Nationale d'Ingénieurs de Metz (ENIM), F-57012 Metz Cedex 01, France

\begin{abstract}
This study has been made to characterize the plastically subsurface layer after orthogonal cutting of on high grade Ti-5N unalloyed titanium with a mean grain size of about 0.5 to $1.8 \mathrm{~mm}$. A home-made sample holder has been specially developed for these experiments and SEM EBSD technique is used to characterized the subsurface layer. In function of the cutting conditions, we have found in subsurface glide (when the cutting speed is low) and when the cutting speed is high some compression twins but also some tension twins which indicated that we have tensile stress state ahead of the tool tip.
\end{abstract}

\author{
Publication History: \\ Received: April 26, 2015 \\ Accepted: June 29, 2015 \\ Published: June 30, 2015 \\ Keywords: \\ High entropy alloys, Superalloys, \\ High temperature strength, Phase \\ stability
}

\section{Introduction}

This present an excellent corrosion resistance combined to highstrength-to-weight ratio properties, and an elevated mechanical resistance together with a low density, titanium alloys are one of the most used materials in the aerospace industries. Despite these features, some titanium alloys such as Ti555-3 [1] present a poor machinability, closely related to their thermal and chemical properties.

A lot of works have been conducted to characterise the plastically deformed subsurface layer submitted to the special case of orthogonal cutting especially for TA6V alloy [2] or for other materials and cutting conditions [3]. Chips are formed during metal cutting process and their micro-structure was investigated together $[4,5]$. It is generally agreed that during metal cutting, the major part of the deformation energy expended is transformed into heat near the cutting edge of the tool $[6,7]$. Depending on the cutting speed, a more or less important amount of the heat is transferred by a pure conduction process to the uncut material ahead of the tool, affecting the mechanical and physical properties of the surface. Because of the temperature rise, it is generally agreed that shear occurs in the near surface of the material. This phenomenon is highlighted by the low conductivity of titanium alloys.

The formation of a "white layer" or of a highly disturbed layer, the description and the macroscopic mechanical properties of the mechanical affected zone are some parts of the main problems discussed in the literature. The depth and the micro-structure of this deformed layer mainly depend not only on the machining parameter but also on the mechanical and physical properties of the material. In conjunction with these studies, new theoretical works have been presented in view to give a better understanding of the cutting process using a polycrystalline modeling of the material [8].

The role of machining on the freshly formed subsurface, on the plastic deformation and on the microstructure damage has been recently studied using new microstructural technique such as transmission electron macroscopy (TEM) or/and scanning electron microscopy (SEM) coupled with electron backscattering diffraction (EBSD). The study of the microscopic phenomenon arising during machining is a difficult task considering polycrystalline material. Some works have been conducted under different machining process for different material such copper alloys [9], tantalum [10] but also on titanium alloys [11].

In the other hand, some works deal with machinability of single crystals which is discussed from the viewpoint of the chip formation and surface topography of the worked piece. One of the main results is that the chip thickness and shear angle varies considerably with the changing crystallographic orientation of materials being cut [12]. Moriwaki et al. [13] observed that the thickness of the chip is influenced by the crystallographic orientation. Some consideration about the role of the crystallographic orientation has been discussed in the case of aluminum alloy by To and al [14]. In this last work, starting with an initial $\left(\begin{array}{lll}0 & 0 & 1\end{array}\right)$ orientation in an aluminum single crystal, a rotation towards (llll $\left.\begin{array}{lll}1 & 1 & 2\end{array}\right)$ and $\left(\begin{array}{lll}1 & 1 & 1\end{array}\right)$ poles was observed indicating that a significant amount of lattice rotation occurred in the deformation layer.

During machining (precision turning) of near-alpha alloy Ti-834 Crawforth and al. [11] determines the effect of cutting speed on the subsurface damage and its subsequent response to thermal exposure. They conclude that subsurface plastic deformation was accommodated in the form of $\{10.2\}$ mechanical twins and intense slip bands. Dargusch and et al. [15] have studied the subsurface deformation after machining of a grade 2 titanium $(99,8 \%)$. This work depicts clearly that some semi-quantitative relationships exists between machining surface speed and the subsurface depth of the deformed layer. They indicates that if these relationships can be quantified, the reliable indicator of the degree of subsurface deformation by formation of twins can be determined.

"Corresponding Author: A. Tidu, Laboratoire d'Étude des Microstructures et de Mécanique des Matériaux (LEM3), CNRS 7239, École Nationale d'Ingénieurs de Metz (ENIM), F-57012 Metz Cedex 01, France; E-mail: tidu@enim.fr

Citation: Tidu A, De Saever A, Schuman C, Bolle B, Chevrier P (2015) Machining of Pure High Grade Titanium: Effect on the Subsurface Microstructure. Int J Metall Mater Eng 1: 108. doi: http://dx.doi.org/10.15344/2455-2372/2015/108

Copyright: () 2015 Tidu et al. This is an open-access article distributed under the terms of the Creative Commons Attribution License, which permits unrestricted use, distribution, and reproduction in any medium, provided the original author and source are credited. 
Citation: Tidu A, De Saever A, Schuman C, Bolle B, Chevrier P (2015) Machining of Pure High Grade Titanium: Effect on the Subsurface Microstructure. Int J Metall Mater Eng 1: 108. doi: http://dx.doi.org/10.15344/2455-2372/2015/108

Page 2 of 5

The ability of pure titanium to deform by twinning is well established. The formation of twins has been investigated for a lot of processes [16, 17] according to the grain orientation with respect to the stress state induced by the process. It appears that the study of twin formation linked to a cutting process can improve our knowledge of the cutting process. Based on the experimental examination, these works $[16,17]$ try to determine out the twin and twin variant selection rule. This rule is essentially established to reveal the physical and mechanical criteria (energy) of variant selection that would be useful for the modeling of the mechanical behavior of the alloys.

Because, the observation of the plastic phenomenon arising during machining is a difficult task for titanium alloy, the main purpose of this paper is to investigate the deformation mechanism induced by machining of high-grade titanium with large grains.

\section{Experimental Procedure}

\section{Studied material}

The cutting tests were carried out on high grade Ti-5N unalloyed titanium (99.9999\%). The as-received material presents mean grains diameter of about 0.5 to $1.8 \mathrm{~mm}$. Samples have been provided as bar in which parallelepiped samples are mechanically cut out. The starting material can be adequately described as a pluri-crystal, i.e. a polycrystalline sample consisting in large grains.

Before any cutting processes, samples are prepared in such a way that the face of the sample parallel to the cutting direction and normal to the tool edge is carefully polished as for metallographic observation. Samples are then embedded in mould with resin and fixed on a special device for the cutting process. The Figure 1 presents the home-made sample holder specially developed for these experiments.

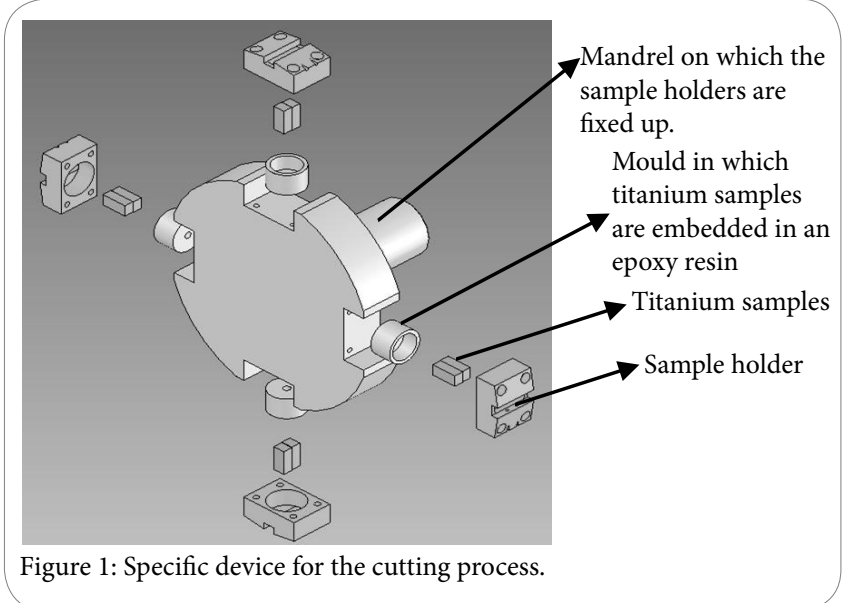

\section{Cutting tests}

Sample has been cut using turning condition and was performed on a computer numerically controlled lathe using carbide tools. The cutting tests are limited to a cutting speed $\mathrm{Vc}<10.5 \mathrm{~m} / \mathrm{s}$. The rake angle is $0^{\circ}$ and the clearance angle is $7^{\circ}$. The tests were carried out without lubrication (dry machining conditions). The cutting depth is fixed to $\mathrm{a}_{\mathrm{p}}=0.3 \mathrm{~mm}$ and the cutting width is $5 \mathrm{~mm}$. The Table 1 gives the detailed machining parameters and cutting parameters.

\section{Samples characterisation}

Samples were mainly analysed by optical and SEM. Local diffraction measurements were carried out using EBSD, based on the automatic acquisition and indexation of Kikuchi diffraction patterns in a SEM. EBSD acquisitions and SEM observations were performed on a 6500F JEOL equipped with the HKL Channel 5 OIM system.

For SEM observations the surface samples were mounted in a resin and mechanically polished, then etched with Kroll reagent (2\% HF, $4 \% \mathrm{HNO}_{3}, 94 \%$ distilled water) for 20 seconds at $20^{\circ} \mathrm{C}$. For EBSD measurements, they were mechanically polished and electrolytically etched, to remove the strain-hardened layer induced by the mechanical polishing. Proper solution $\left(10 \% \mathrm{HNO}_{3}, 90 \% \mathrm{CH}_{3} \mathrm{OH}\right)$ at a working potential of $17 \mathrm{~V}$ for 5 seconds was used.

The machined surface (including the machining direction) is always perpendicular to the polished surface which is observed without any preparation after cutting.

\begin{tabular}{|l|l|l|}
\hline $\mathrm{Vc}(\mathrm{m} / \mathrm{s})$ & ap $(\mathrm{mm})$ & ae $(\mathrm{mm})$ \\
\hline 1.7 & 0.3 & 5 \\
\hline 2.6 & 0.3 & 5 \\
\hline 4.2 & 0.3 & 5 \\
\hline 6.3 & 0.3 & 5 \\
\hline 8.4 & 0.3 & 5 \\
\hline 10.5 & 0.3 & 5 \\
\hline
\end{tabular}

Table 1: Cutting parameters.

\section{Results and Discussion}

Typical microstructures are shown in Figure 2 for the as-received $\mathrm{Ti}$ $5 \mathrm{~N}$ : the nearly equiaxed grains have an average grain size of $1500 \mu \mathrm{m}$. No traces of slip plane and no twins are observed at the surface and on the cross-section of the samples. The Figure 3 presents the crosssection of the as-machined material with the lower (3a) and higher (3b) Vc. The main observation is the formation of three different areas including two special areas containing highly plastically deformed material presenting more or less small grains, a plastically deformed area presenting twins or slip lines, and an unaffected area.

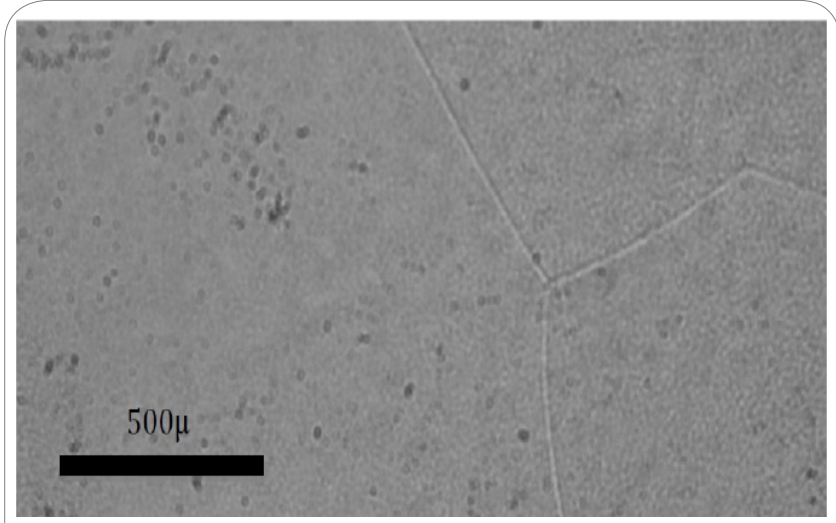

Figure 2: Optical micrography of the observed surface of the high grade titanium before cutting.

It is well known that twinning plays an important role in the deformation process of pure titanium. For all machined samples, twins runs from the near sub-surface to the interior at angles depending on the orientation of the grain before machining. Sometimes, twins appear to pass through adjacent grains to give another twin with 
Citation: Tidu A, De Saever A, Schuman C, Bolle B, Chevrier P (2015) Machining of Pure High Grade Titanium: Effect on the Subsurface Microstructure. Int J Metall Mater Eng 1: 108. doi: http://dx.doi.org/10.15344/2455-2372/2015/108

Page 3 of 5

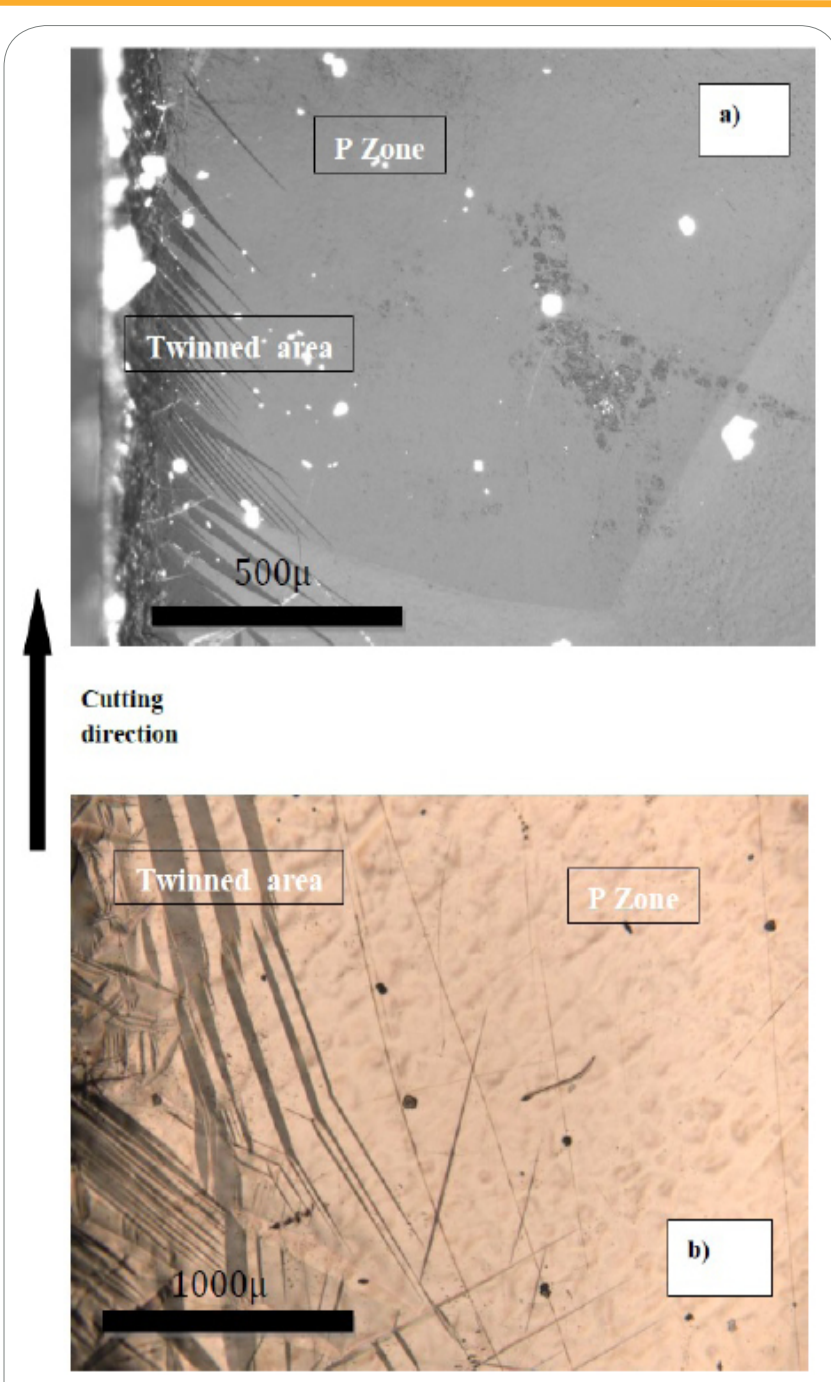

Figure 3: Optical micrograph of the transverse sections a) $\mathrm{Vc}=$ $1.7 \mathrm{~m} / \mathrm{s}$ and $\mathrm{b}$ ) $\mathrm{Vc}=10.5 \mathrm{~m} / \mathrm{s}$.

different orientation. The twinned region contains essentially twins that can be seen as formed by small and fine twins and an area with longer and larger twins. Assuming that twin density is linked to the total twinned area, it is found that the twin density increases with the cutting speed. This result confirms the results obtained by Dargusch and al. [15].

If the twinned region shows large and long twins having size depending on the cutting speed, in the last area away from the machined surface, only traces of slip lines are observed. They are limited by (and do not pass through) the grain boundary. By using simple measurements of the angles of these lines with respect to the machined surface and orientation given by EBSD measurement, we clearly show that these lines are compatible with prismatic glide.

For different cutting speed, the widths of these different areas have been measured and the measured values are depicted in Figure 4. The width of the twinned area increases with cutting speed while the width of the plastically deformed area decreases.

The Figure 5 shows that the near sub-surface layer is highly deformed. The width of this area is about $100 \mu \mathrm{m}$. The formation of

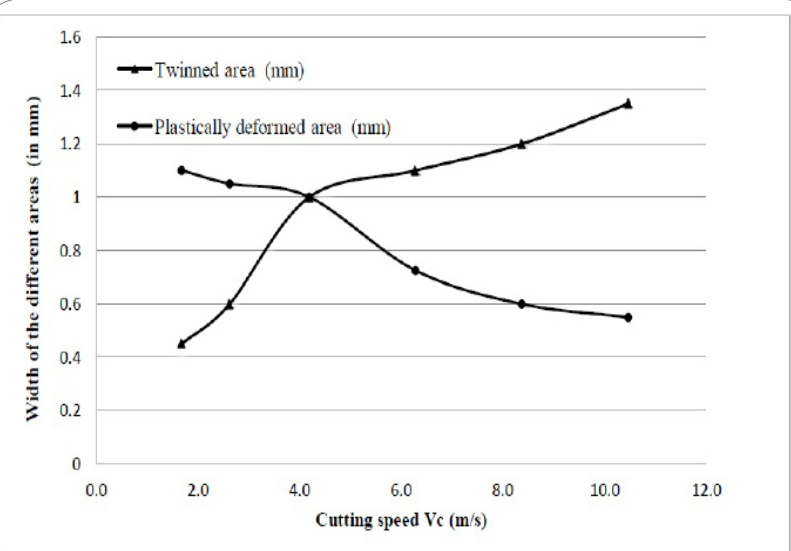

Figure 4: Evolution of the width of the twinned and of the plastically deformed layer according to the cutting speed.

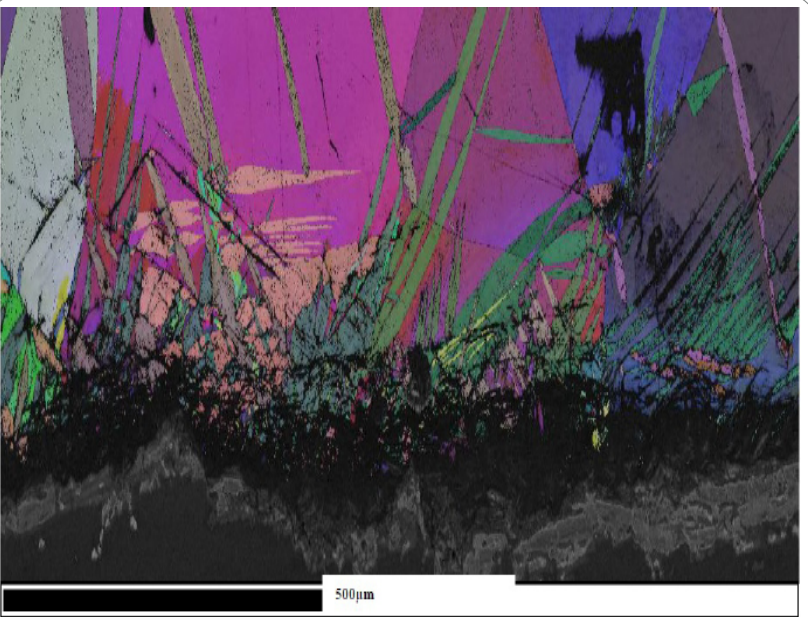

Figure 5: EBSD analysis of the sub-surface $(\mathrm{Vc}=8.4 \mathrm{~m} / \mathrm{s})$.

micro-structured grains during cutting is not a clearly depicted fact. A careful examination of the EBSD map and micrograph Figure 5 shows clearly that part of twins are observed inside the mechanically deformed layer. This indicates that twins are formed before the formation of the deformed layer. The formation of this plastically deformed layer is the result of the intense stress imposed by the tool in the material and more specifically on the surface. A thin titanium oxide layer (lesser than $1 \mu \mathrm{m}$ ) is also probably formed on the surface.

Beside this first layer, another point is also clearly observed: twins are curved. The measured disorientation inside the twins using EBSD mapping, is always lesser than $0.5^{\circ}$. We can explain this by the fact these twins are dragged towards the cutting direction according to a shear deformation process. This process is a well known process and is also observed for polycrystalline material such as TA6V alloy [2].

The crystallographic orientations of the twin and of the prior grain are determined by EBSD, and then the disorientation between them can be calculated. Each twin produced its own c-axis tilt. In our case, we obtain tension twin of type $\mathrm{T} 1(10 \overline{12})$, the $\mathrm{c}$-axis are $85^{\circ}$ apart from the prior grain. We don't measured compression twin $\mathrm{C}(1 \overline{1} \overline{2} 2)$, no more tension twin $\mathrm{T} 2((1 \overline{12})$.

Note that by EBSD the orientation Euler angles $\left\{\varphi_{1}, \Phi, \varphi_{2}\right\}$ are determined in the $(\mathrm{ND}, \mathrm{RD}=$ cutting direction) frame and are 
Citation: Tidu A, De Saever A, Schuman C, Bolle B, Chevrier P (2015) Machining of Pure High Grade Titanium: Effect on the Subsurface Microstructure. Int J Metall Mater Eng 1: 108. doi: http://dx.doi.org/10.15344/2455-2372/2015/108

Page 4 of 5

recalculated for the (RD,TD) frame. The $(00.2)$ pole figures (corresponding to the c-axis) of the twinned grains can be drawn (Figures $6 \mathrm{c}$ and $7 \mathrm{c}$ ). It is also clearly observed that all grains showing twins are more or less longer than grains showing plastic slip that are more equiaxed (Figure 6a and 7a). It is also possible to identify the variants that have been activated by trace analysis (Figure $6 \mathrm{~b}$ and $7 \mathrm{~b}$ ). Schuman et al. [16] and Wang et al. [17] have shown that for cold rolling and channel die extrusion processes, the choice of the twin is governed by the following condition: the plastic energy needing for the propagation $\left(\mathrm{W}_{\text {twin }}\right)$ of a twin should be positive. Because $\tau$ and $\gamma$ are positive, this condition must also be true in the macroscopic frame:

$$
\mathrm{W}_{\text {twin }}=\left.\tau \gamma\right|_{\text {twin frame }}=\left.\sigma_{\mathrm{ij}} \varepsilon_{\mathrm{ij}}^{\prime}\right|_{\text {sample frame }}
$$

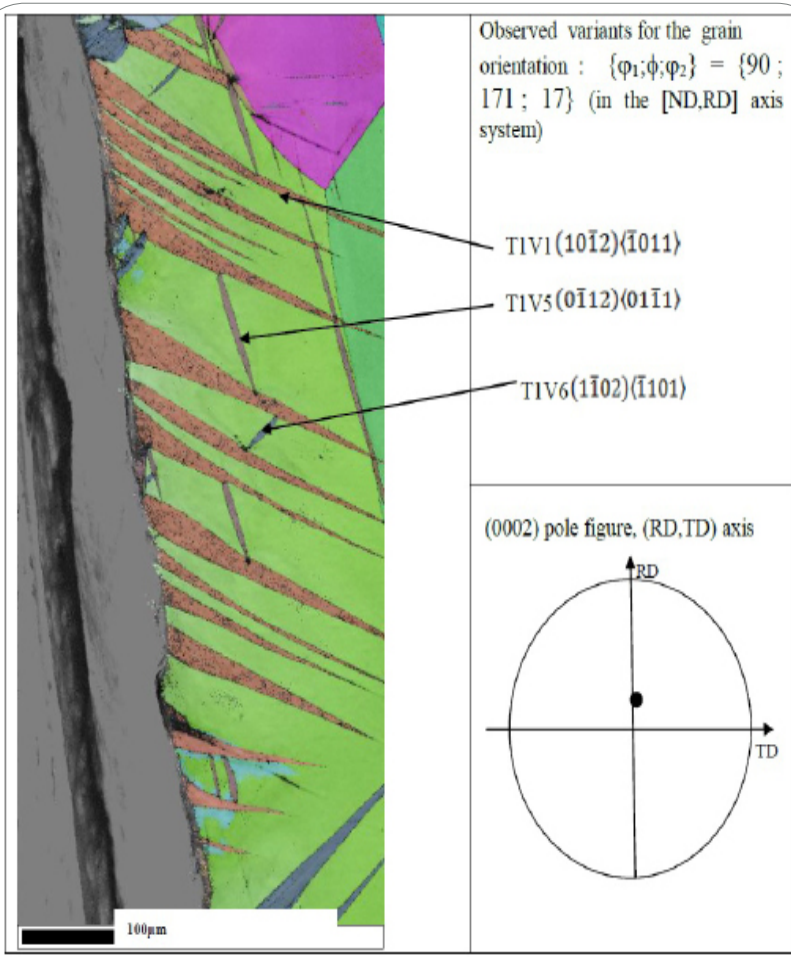

Figure 6: EBSD map and orientation analysis of the c-axis twin for a cutting speed of $\mathrm{Vc}=2.6 \mathrm{~m} / \mathrm{s}$.

where is the critical resolved shear stress required (=shear stress $\tau$ in the twin frame expressed in the sample frame for the T1 or C or T2 twins) to activate the twinning system and $\varepsilon$ 'ij is the corresponding twinning deformation (shear $\gamma$ express in the sample frame) We suppose that a compressive or a tensile force is normal to the plane of the sample, then the stress tensor is formed as a unique component

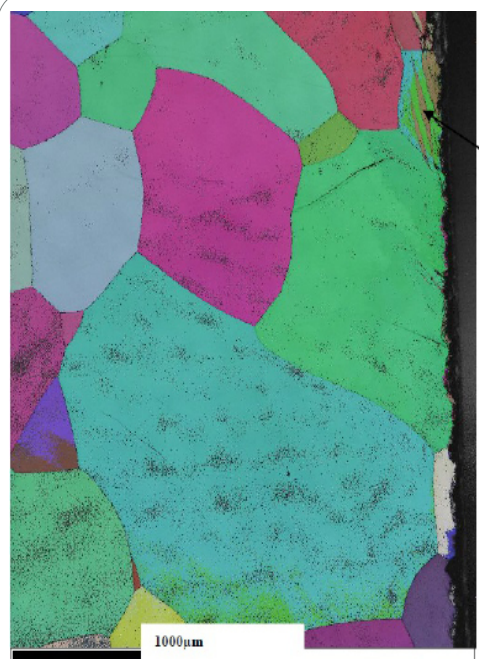

Observed variants for the grain Orientation : $\left\{\varphi_{1} ; \phi ; \varphi_{2}\right\}=\{24$; 64:58\} (in the $[\mathrm{ND}, \mathrm{RD}]$ axis system)

used variant: $\operatorname{T1V} 4(\overline{1} 012)\langle 10 \overline{1} 1\rangle$

(00.2) pole figure (axis system (RD,TD])

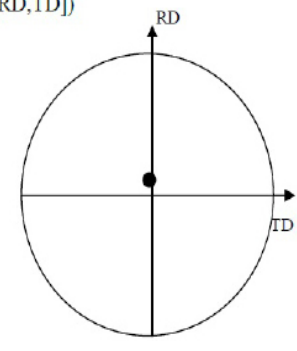

Figure 7: EBSD map and orientation analysis of the twin c-axis for a cutting speed of $\mathrm{Vc}=1.7 \mathrm{~m} / \mathrm{s}$.

$\sigma_{33}$ then $\sigma_{i j}=\sigma_{33}$. The twinning system will be active when the resolved shear stress reaches the corresponding critical value.

The choice of a tension deformation mode can be explained as follow. The orientation of the prior grain is known, and then it is easy to calculate the deformation in the macroscopic frame according to Martin et al. [18]. As a result, we obtain a positive value for $\varepsilon^{\prime}$ for the tension twin and negative value for compressive twin: then the c-axis is near the ND direction (Table 2). If the strain is positive, the positivity of the mechanical energy is obtained only for tensile stress state. Twinning can then only operate for orientations of the $c$-axis near the ND direction. In other words, for c-axis near the ND direction, a compressive state of stress activates compressive twins of type C: in our case, only tensile twin of type T1 are observed meaning that the state of stress is tensile.

The zones of activity of the different twinning systems can be determined for all the $\mathrm{c}$ axis positions and for a tensile stress state parallel to DN. The determination of the Schmid factor (SF) cannot be sufficient to determine the active variant. It can be easily seen in Table 2 that the variant used doesn't have the higher SF. In fact, this choice is also governed by the $\frac{\varepsilon_{33}}{\sqrt{L}}$ criterion; this ratio must be maximum [16] where $\mathrm{L}$ is the mean free path that can follow the twin in the grain. Each time a twin variant is formed in a grain, the length of the mean free path change. This is the reason why the same variant is observed several times and sometimes other variant depending on the ratio $\frac{\varepsilon_{33}^{\prime}}{\sqrt{L}}$.

\begin{tabular}{|l|l|l|l|l|l|l|l|}
\hline Tension twin & Schmid factor & \multicolumn{1}{l|}{$\varepsilon_{33}^{\prime}$} & \multicolumn{2}{l|}{ Compression twin } & \multicolumn{2}{l|}{ Schmid factor } \\
\hline T1V1 & $(1012)(1011)$ & 0.460 & 0.085 & CV1 & $(1122)(1123)$ & & -0.489 \\
\hline T1V2 & $(0112)(011)$ & 0.490 & 0.085 & CV2 & $(2112)(2113)$ & -0.105 \\
\hline T1V3 & $(1102)(1101)$ & 0.487 & 0.085 & CV3 & $(1212)(1213)$ & -0.374 & -0.374 \\
\hline T1V4 & $(1012)(1011)$ & 0.490 & 0.084 & CV4 & $(1122)(1123)$ & -0.091 & -0.440 \\
\hline T1V5 & $(0112)(0111)$ & 0.476 & 0.081 & CV5 & $(2112)(2113)$ & -0.080 \\
\hline T1V6 & $(1102)(1101)$ & 0.476 & 0.082 & CV6 & $(1212)(1213)$ & -0.489 & -0.440 \\
\hline
\end{tabular}

Table 2: $\varepsilon_{33}^{\prime}$ and Schmid factor for the different variant (bold letter for the used variants in this work). 
Citation: Tidu A, De Saever A, Schuman C, Bolle B, Chevrier P (2015) Machining of Pure High Grade Titanium: Effect on the Subsurface Microstructure. Int J Metall Mater Eng 1: 108. doi: http://dx.doi.org/10.15344/2455-2372/2015/108

Page 5 of 5

Using EBSD measurement and slip line orientation, Thomas and al. [19] conclude that it is not possible to accurately determine the resolved shear stress and that the stress state immediately below the machined surface is rather complex.

Recent modeling experiment has been conduct for titanium alloys using a polycrystalline model [18]. These results show clearly that microstructure and related orientation of grains have an influence on the cutting process. But they don't take into account the plastic mechanism inside the grains. The results obtained in these works are concerned by the final state of stress and does not given the evolution of the stress in part of the material. But it is well known that when machining a feed force and a cutting force are active in front of the tool tip.

According to our observations, it seems that near or in front of the tool edge, the initial state of stress is tensile as it can be deduced form the twin analysis. The final state of stress results of the successive mechanisms: tensile strain due to the feed force and compressive cutting force applied to the material. The final state of stress results of the combination of these different mechanisms and on the temperature rising during cutting.

\section{Conclusion}

This study presents the characteristic of the subsurface of high grade titanium after machining. It has been established a correlation between machining speed and the twin density as a function of depth under the machined surface.

The different observation made in this work cannot evidently be observed for polycrystalline material because of the smallness of the grains and on the difficulty in the determination of the orientation of the slip lines.

We have described the subsurface in three parts. The first very thin layer which cannot be measured accurately is highly deformed and no information about its microstructure could be presented. The effect of the cutting speed on the different width of the plastically areas is clearly depicted. The width of the twinned region increases whereas the width of the area showing trace of slip plane decreases. Another observation is the increasing of the width of the lenticular twins as the speed increases. This point indicates clearly that the twinning density which can be seen proportional to the "total twinned surface" evolves in the same manner. Twinning is the predominant mechanism of deformation for higher cutting speed while slip is predominant for smaller cutting speed.

We have shown that a tensile state of stress is responsible of the formation of twins ahead of the tool tip. To verify our experimental results, numerical calculations could be made. Actually it is impossible to explain the twin nucleation and the twin growth because these phenomenons are still poorly understood in many HCP and also in titanium.

\section{Competing Interests}

The authors have declared that no competing interests exist.

\section{Author Contributions}

All the authors substantially contributed to the study conception and design as well as the acquisition and interpretation of the data and drafting the manuscript.

\section{References}

1. Arrazola PJ, Garay A, Iriarte LM, Armendia M, Marya S, et al. (2009) Machinability of titanium alloys (Ti6Al4V and Ti555.3). J Mater Process Tech 209: 2223-2230.

2. Velasquez JD, Tidu A, Bolle B, ChevrierP, Fundenberger JJ (2010) Subsurface analysis of high speed machined TA6V. Material Sci Eng A: 527: 2572-2578.

3. M'Saoubi R, Ryde $L$ (2005) Application of the EBSD technique for the characterisation of deformation zones in metal cutting. Mater Sci Eng A 405: 339-349.

4. Komanduri R, Von Turkovich BF (1981) New observations on the mechanism of chip formation when machining titanium alloys. Wear 69: 179-188.

5. Puerta Velasquez JD, Bolle B, Chevrier P, Tidu A (2007) Metallurgical study of chips obtained by high speed machining of Ti-6wt.\%Al-4wt.\%V alloy. Mater Sci Eng A 452-453: 469-474.

6. Barry j, Byrne G, Lennon D (2001) Observations on chip formation and acoustic emission in machining Ti-6Al-4V alloy. Int $\mathrm{J}$ Mach Tools Manuf 41: 1055-1070.

7. BurnsTJ, Davies MA (2002) On repeated adiabatic shear band formation during high-speed machining. Int J Plast 18: 487-506.

8. Zhang Y, Mabrouki T, Nélias D, Courbon C, Rech J, et al. (2012) Cutting simulation capabilities based on crystal plasticity theory and discrete cohesive elements. J Mater Process Tech 212: 936-953.

9. Hung NP, Zhong ZW, Lee KK, Chai CF (1999) Precision grinding and facing of copper-beryllium alloys. Precision Eng 23: 293-304.

10. Sarkar J, Gillman PS (2008) Imaging of ultrafine grains in machined tantalum using a focused ion beam. Scripta Materalia 59: 301-304.

11. Crawforth P, Wynne B, Turner S, Jackson M (2012) Subsurface deformation during precision turning of a near-alpha titanium alloy. Scripta Materialia 67 : 842-845.

12. Lee WB, To S, Cheung CF (2000) Effect of crystallographic orientation in diamond turning of copper single crystals. Scripta Materialia 42: 937-945.

13. Moriwaki T, Okuda K, Shen JG (1993) Study of ultraprecision orthogonal microdiamond cutting of single-crystal copper. JSME Int J Series C 36: 400-406.

14. To S, Lee WB, Cheung CF (2003) Orientation changes of aluminum single crystals in ultra-precision diamond turning. J Materials Process Tech 140: 346-351.

15. Dargusch MS, Zhang MX, Palanisamy S, Buddery AJM, St John DH (2008) Subsurface deformation after dry machining of grade 2 Titanium Adv Eng Mat 10: 85-88

16. Schuman C, Bao L, Lecomte JS, Zhang Y, Raulot JM, (2012) A New Variant Selection Criterion for Twin variants in Titanium alloys (part2). Adv Eng Mat 14.

17. Wang S, Schuman C, Bao L, Lecomte JS, Zhang Y, et al. (2012) Variant Selection Criterion for Twin Variants in Titanium alloys deformed by rolling. Acta Materialia 60: 3912-3919.

18. Martin E, Capolongo L, Jiang L, Jonas JJ (2010) Variant selection during secondary twinning in Mg-3\%Al Acta Mater 58: 3970-3983.

19. Thomas M, Turner S, Jackson M (2010) Microstructural damage during high-speed milling of titanium alloys. Scripta Materialia 62: 250-253. 